International Journal of Current Advanced Research

ISSN: O: 2319-6475, ISSN: P: 2319 - 6505, Impact Factor: SJIF: 5.995

Available Online at www.journalijcar.org

Volume 6; Issue 4; April 2017; Page No. 3203-3205

DOI: http://dx.doi.org/10.24327/ijcar.2017.3205.0225

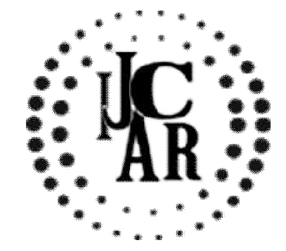

Research Article

\title{
THE STUDY OF RELATION BETWEEN ACHIEVEMENT MOTIVATION LEVEL AND FEATURES OF LOSS EXPERIENCE OF SIGNIFICANT OTHER
}

\section{Ekaterina Karacheva}

Department of Psychological Help and Resocialization, Moscow State University, Russian Federation

\begin{tabular}{|c|c|}
\hline 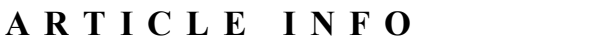 & $A B S T A C T$ \\
\hline Article History: & \multirow{4}{*}{$\begin{array}{l}\text { The article presents the results of the study of the connection between the achievement } \\
\text { motivation and the peculiarities of experiencing the loss of a significant Other. The } \\
\text { classical approaches to understanding grief and loss are analyzed, the significance of } \\
\text { psychological personality work which gives opportunity to cope with grief effectively, to } \\
\text { survive it and to develop the experience as a successful result of grief is shown. It is } \\
\text { assumed that the two motivational determinants - seek of success and fear of failure - can } \\
\text { influence the processes of experiencing loss and coping with grief, while the experience of } \\
\text { grief itself affects motivational determinants of the individual. The relationship between } \\
\text { achievement motivation in the form of a motive for success and the motive for fear of } \\
\text { failure and traumatic experience of grief in the form of intrusion of experience and } \\
\text { avoidance of experience is mediated by the degree of arbitrariness and involvement in } \\
\text { personality work that individual accomplish with his own experience of loss. }\end{array}$} \\
\hline $\begin{array}{l}\text { Received } 26^{\text {th }} \text { January, } 2017 \\
\text { Received in revised form } 8^{\text {th }} \text { February, } 2017 \\
\text { Accepted } 22^{\text {nd }} \text { March, } 2017 \\
\text { Published online } 28^{\text {th }} \text { April, } 2017\end{array}$ & \\
\hline Key words: & \\
\hline $\begin{array}{l}\text { Achievement motivation, seek of success, fear } \\
\text { of failure, loss, grief, grief work, personality } \\
\text { work, post-traumatic stress. }\end{array}$ & \\
\hline
\end{tabular}

Copyright $₫ 2017$ Ekaterina Karacheva. This is an open access article distributed under the Creative Commons Attribution License, which permits unrestricted use, distribution, and reproduction in any medium, provided the original work is properly cited.

\section{INTRODUCTION}

Research of loss experience in psychology are usually devoted to studying the characteristics of these experiences, or the symptomology of grief, assessing the degree of "normality" or abnormal grieving, describing the stages, phases of the process, the tasks that grieving person have to solve for coping with grief (Bowlby, 1999; Lindemann, 1984; Bonanno et al., 2005; Parkes, 1996; Stroebe, 2005). Thus, the main emphasis in the psychology of loss is made on the processes of experiencing grief and coping with it. However, if we interpret the experience of grief as the "grief work " in the initial psychological formulation of this issue by S.Freud, that is, to start from the fact that the process is aimed at breaking ties with the lost one and establishing new ties, then a number of unresolved issues are revealed (Freud, 1981).

Indeed, the psychological work aimed at reconstructing the image and transforming attachment, raises the question of the determinants, psychological mechanisms and regulations of this work. Among them, personal motivational dispositions are of particular importance. They set and define both general sources of motivation and common objective boundaries for specifying and objectifying the direction of mental process. Among these motivational dispositions, the need for achievement is more important, or more broadly, achievement motivation, which is responsible for motivating and directing

*Corresponding author: Ekaterina Karacheva Department of Psychological Help and Resocialization, Moscow State University, Russian Federation behavior toward certain objective results, outcomes and standards, in the broadest sense - achieving success or avoiding failure (Heckhausen, 1967; Atkinson, 1957). The purpose of our research is to identify the connection between the experience of a person losing a significant Other and the dynamics of motivation - motivation to achieve in the form of avoidance of failure

We assume that the two motivational determinants- seek of success and avoidance of failure-can affect the character of the processes of experiencing loss and coping with grief. We find the basis of this general hypothesis in two main processes that characterize the experience of grief and loss.

In these critical conditions a person, on the one hand, confronts with loss, that is, seeks to experience the experience of loss and to develop the experience as a successful result, and on the other hand, people experiencing loss show the avoidance of this experience, which is usually considered as a failure of processing their own experience (MagomedEminov, 1998, 2001, 2007). Hence the focus on experiencing or avoiding experience can have certain connections with two motivational tendencies: "achievement" or "avoidance" including the outcome of the process of experience as successful or unsuccessful. In addition, the ratio of these two trends will be determined, first of all, by the temporal factor (that is how much time has passed since the moment of loss) the impact of which we also plan to assess. 


\section{MATERIALS AND METHODS}

The study involved 30 people, including 9 men and 21 women. The age of the subjects is $23-45$ years. The average prescription of loss in subjects at the time of participation in the study was at least 1 year. The predominant type of loss among the representatives of our sample was the death of the parent $-60 \%$, the second place was the death of the spouse $27 \%$, the third- death of the child $-3 \%$. In most cases, death occurred as a result of the disease, but we also analyzed cases of sudden loss as a result of an accident.

To evaluate the motivation factors and the intensity of the experience of the traumatic experience of loss, the following methods were used: 1) Test of Impact of Life Events (M.Horowitz) for assessing the intensity of traumatic experience; 2) Methodology "Motivation to achieve success and avoid failure"; 3) J.Nutten's "Uncompleted Proposals" (all three in adaptation of M.Sh. Magomed-Eminov).

\section{RESULTS}

The data obtained show that the loss of a loved one is perceived as traumatic stress by the majority of subjects, regardless of the forms of its manifestation. At the same time, the stressful character of this event is cross-temporal, that is, it does not depend on the time that has passed since the loss. The intensity of the experience can vary with time - weaken, reduce. However, even after a few years, situational triggers can re-activate the acute experience of grief. The part of the sample that detected the traumatic nature of the loss experience was used to estimate the distress index and the motivational index for striving for success and avoiding failure.

To assess the relationship between achievement motivation of and intensity of traumatic experience in two ways - positive fixation on loss (experiencing grief) and negative fixation on loss (avoiding the experience of grief) - the following criterion for differentiating the invasion index of experience and the index of avoidance of experience was used. The invasion index of the experience was compiled on the basis of a high score for invasion of experience and a low score for avoiding the experience. The index of avoidance of experience was built on the basis of a low score on traumatic intrusion of experience and a high score of traumatic avoidance. On the basis of this differentiation, four groups of conjugation of the indices of the motivation for success and avoidance of failure and two indices for experiencing grief were identified. The data show that there is a significant link between the high failure avoidance index (MF) and the avoidance of experience index (AE), and between the motivation for success (MS) and the invasion index of the experience (IE) $(\chi 2=11.25, \mathrm{p}<0.001)$.

To interpret the data, we turned to sample distribution by the characteristics of grief experience. The study showed that the majority of subjects $(87 \%)$ showed average intensity of posttraumatic stress reactions to traumatic stressors as a result of loss of loved ones; $13 \%$ of people with traumatic experiences of losing a loved one tend to avoid traumatic events, they tend to avoid feelings, thoughts, situations related to the death of loved ones; $23 \%$ were not focused on avoiding feelings and thoughts about situations related to the death of loved ones; $27 \%$ note that they experienced nightmares, obsessive thoughts, images and feelings associated with the loss of loved ones.

\section{DISCUSSION}

These data make it clear that there is a positive link between the desire for success (MS) and the invasion of experience (IE) among those who are not oriented toward avoiding thoughts and feelings about the situation of loss (23\%), but the experience is of an arbitrary positive nature. And in the group for which the invasion of experience is also characteristic, but already in the form of involuntary, or compulsive, engulfment with the experience (nightmares, obsessions and feelings), a positive connection with avoiding failure motive is revealed.

Our data show, in general, the following relationships between the motivation and experience of the loss experience: 1) in people who survived the loss of a loved one, the motivation for avoiding failures prevails; 2) the motivation to avoid failure in people who survived the loss of a loved one, the higher - the more people try to avoid thinking and feeling about loss; 3) the motivation to avoid failure in people who survived the loss of a loved oneis higher - the higher the level of their stress; 4) the motivation to avoid failure in people who survived the loss of a loved one is higher - the less time has passed since the loss.

\section{CONCLUSIONS}

1. The study confirms the existence of connection between the achievement motivation and experiencing the loss of significant Other. However, depending on the time that has passed since the loss, as well as onpersonality work accomplished with his loss experience (avoids thought, feelings about what happened, is closed from social contact, etc.), the character of this connection with the motivational tendency (motivation to achieve or motivation to avoid failures) depends.

2. The results of the study show the presence of a significant link between the high index of the avoidance of failure motive and the high index of avoiding the experience of loss-avoiding feelings, thoughts, situations related to the death of a loved one.

3. There is a positive relationship between the motivation for success and the high index of the invasion of experience, when this process has the character of an arbitrary recollection of experience.

4. Motivation of avoidance is positively associated with the intrusion of experience when the intrusion of experience is involuntary, compulsive, intrusive.

5. The relationship between motivation for achievement in the form of a motive to seek success and the motive to avoid failure and traumatic experience of grief in the form of intrusion of experience and avoidance of experience is mediated by the degree of arbitrariness in the work of the personality that a person makes over his own experience of experiencing loss.

\section{References}

1. Bowlby J. (1999) [1969]: Attachment. Attachment and Loss (vol. 1) (2nd ed.). New York: Basic Books. ISBN 
0-465-00543-8. LCCN 00266879. OCLC 11442968. NLM 8412414.

2. Lindemann E. (1984) the Clinic of Acute Grief. // Psychology of emotions. Ed. VC. Vilyunas. - Moscow.

3. Magomed-Eminov M.Sh. (2001) Achievement motivation: structure and mechanisms. Moscow.

4. Magomed-Eminov M. Sh. (2007) Positive psychology: in 2 vols. Moscow, PARF.

5. Magomed-EminovM.Sh. (1998) Transformation of personality. Moscow: PARF.

6. Heckhausen H. (1967) The Anatomy of achievement motivation. Academic Press, New York.

7. Atkinson J. W. Motivational determinants of risktaking behavior // Psychol. Rev. 1957. N 64. P. 359372 .
8. Bonanno, G.A. et al. (2005) Resilience to Loss in Bereaved Spouses, Bereaved Parents, and Bereaved Gay Men // Journal of Personality and Social Psychology, 88, 5, 827-843.

9. Freud, S. (1981) Mourning and Melancholia. C.P. St. Vol.XIV.London. Hogart Press. [Volkmann's] SammlungklinisherVortrlge, Leipzig.

10. Parkes, C.M. (1996) Bereavement: Studies of grief in adult life. 3rd ed. London.

11. Stroebe, M. (2005) Attachment in Coping With Bereavement: A Theological Integration // Review of General Psychology, 9 (1), 48-66.

12. Wortman, C.B., Silver, R.C. (2001) The myths of coping with loss revisited. - In M.S. Stroebe, R.O. Hansson, W. Stroebe, H. Schut (Eds.). Handbook of bereavement research: Consequences, coping and care (pp. 405-429). - Washington, DC: American Psychological Association.

\section{How to cite this article:}

EkaterinaKaracheva (2017) ' The Study Of Relation Between Achievement Motivation Level And Features Of Loss Experience Of Significant Other', International Journal of Current Advanced Research, 06(04), pp. 3203-3205.

DOI: http://dx.doi.org/10.24327/ijcar.2017.3205.0225 